\title{
Development of damage detection parameters over the lifetime of a rolling element bearing
}

\author{
Matti Savolainen, Arto Lehtovaara \\ Materials Science and Environmental Engineering, Tampere University, Finland \\ Corresponding author: Matti Savolainen (matti.j.savolainen@tuni.fi)
}

\begin{abstract}
This paper presents the trends of damage detection parameters over the lifetime of a rolling element bearing. In the experimental part, a series of bearing tests was performed using the twin-disc test device, until the monitored bearing was severely worn. This was followed by the analysis of measured acceleration and acoustic emission data in a constant load condition, but also as loaded with impact-type loading. The results showed that traditionally used parameters, such as kurtosis and the root mean square (RMS), can indicate whether the bearing is damaged or not in a non-impact load condition. However, especially under impact loading, the parameters based on acoustic emission data showed good performance and enabled monitoring of progress of the bearing damage.
\end{abstract}

Keywords: Rolling element bearing, impact load, damage detection, acoustic emission

\section{Introduction}

Rolling element bearings are widely used in machinery because of their good trade-off between size and cost to performance. Their life expectancy can also be calculated quite accurately, especially when the load and the working conditions are well known. However, in many applications, the conditions vary significantly leading to difficulty in reliably defining maintenance intervals. To enable the costeffective planning of service, critical bearings are often closely monitored.

Typically, the rolling element bearing condition in real machinery has been monitored through trend analysis. Often the analysis is based on monitoring changes in measured acceleration levels or the root mean square (RMS) values and guidance for such measurements and diagnostics are also given in standards [1, 2]. Methods based on monitoring spectral changes, calculated from the measured acceleration data, have long been used to indicate bearing damage as well. Another widely used method has been to track impulsiveness of the obtained acceleration data, where high impulsivity is considered to be caused for instance by a spall on the surface of a bearing component [3]. Although the above methods have been successfully used for decades, the results may be heavily influenced not only by the loading of the machine, but also by disturbing external loads that interfere with the measured signal $[3,4]$. Therefore, a lot of research has been conducted to separate the response originating from a bearing fault from other data, as discussed in Refs. [4-7]. Although these methods have been found to work well in several applications, they may be case-specific or require significant computing power in order to be used in online monitoring systems.

Acoustic emission (AE) is a technology for detecting elastic waves generated by the occurrence of microscale defects. In the early days it was developed for the nondestructive testing of static structures such as pressure vessels and tanks [8]. Quite recently studies have been published about monitoring rolling element bearing condition by utilizing AE [9-11]. Additionally, in papers by Elasha et al. [12] and Cornel et al. [13], AE was found to be a more efficient approach for finding damage in bearings in comparison to acceleration data.

Traditionally, the rolling element bearing testing has been conducted as full-scale bearing testing, or as benchtype testing, where a limited number of rolling elements is tested with a specific machine imitating real operating conditions [14]. The testing has focused on ranking materials and lubricants, or on the research of bearing failure modes, such as smearing, micropitting or white etching cracks [14-17]. In full-scale testing, the test arrangements often enable the possibility of testing multiple bearings at the same time as well as the introduction of specific operation conditions and load sequences that vary in the axial and/or in the radial directions $[18,19]$. Usually, the duration of the test needed for the rolling element bearing to fail is long and therefore mainly two approaches have been utilised to accelerate the endurance testing: increased level of applied load or increased operating speed [18]. Hence, many comprehensive papers dealing with bearing failures and detection of them, have focused on validating damage 

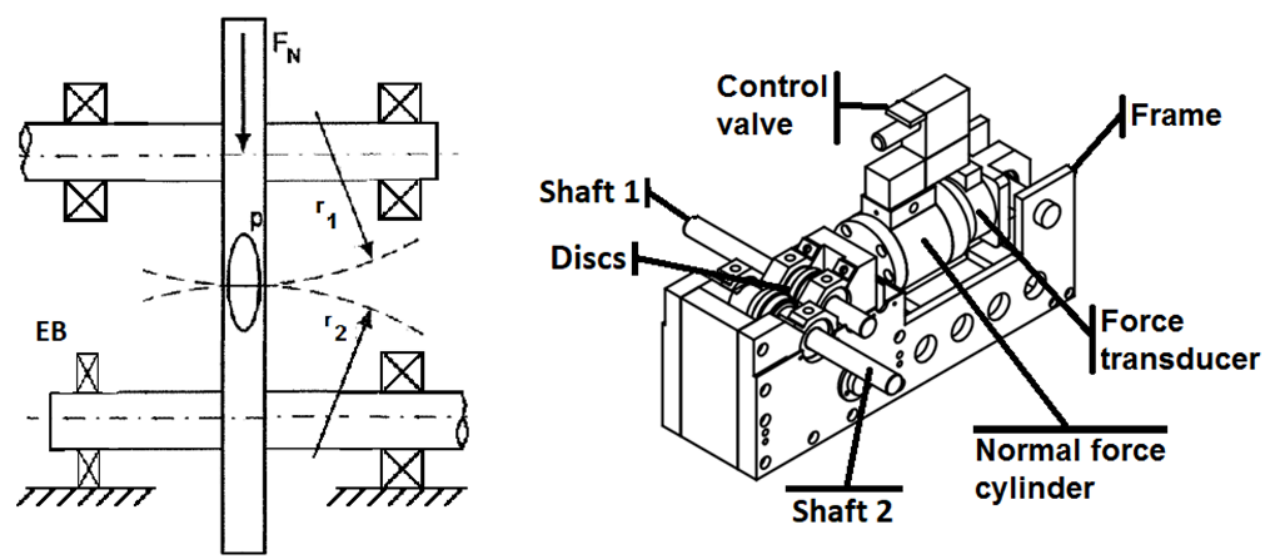

Fig. 1. The principle of the twin-disc testing on the left, where the examined bearing is marked with "EB". On the right is the real load frame of the device used in this study.

detection methods typically by observing bearings with artificial damage or by using real machinery with damaged bearings [7, 9-13, 20-22].

The twin-disc test device has been traditionally used to study phenomena occurring between the discs, which is considered to mimic the condition between gear teeth, for instance, in spiral bevel gears. Over the years, research using the twin-disc test device has focused on studying the formation of pitting or micropitting, the effect of surface roughness, wear, and the behaviour of friction under different load conditions, scuffing and subsurface-initiated fatigue [23-31].

Although rolling element bearings have been massively studied over the years, papers dealing with the trend of monitoring parameters over the lifetime of bearings by considering also external distorting loads are challenging to find. This paper presents the development of values of typical damage detection parameters over the bearing lifespan under constant or combined constant and impact loading. In the experimental part, several bearings are tested in an accelerated state, until they are damaged. In the second part of the work, the measured acceleration response as well as acoustic emission data are analysed. The results show that traditionally used parameters such as kurtosis and RMS can indicate a damaged bearing in a situation where the system is operating without any impact loading. However, when an external impact-type loading interferes with the measured device, as it is often the case in real machinery working in harsh condition, the reliability of the result with these parameters decreases. In turn, the parameters calculated from the acoustic emission data showed promising outcome also under impact loading not only in detecting bearing damage, but also in monitoring the progress of the damage.

\section{Test arrangement}

The tests were conducted by using an in-house developed twin-disc test device. Traditionally, the main purpose of the device has been on the research of phenomena occurring in the contact of the discs. The principle of the twin-disc system as well as the load frame of the device are illustrated in Fig. 1. The load force $F_{N}$ generates the radial movement of one of the shafts pushing the discs together through the supporting bearings. The force is produced by a hydraulic cylinder, which is driven by a control valve that adjusts the loading with the aid of the signal from a force transducer mounted behind the cylinder. There are four bearings in the test arrangement so that each bearing carries half of the total radial load. The rotation of the shafts is generated by electric motors, which are driven by frequency converters.

A separate hydraulic unit provides pressurised lubrication circulation to the disc contact as well as to the bearings on the shafts. A micro-controller automatically adjusts the lubricant temperature, which can be set between $25{ }^{\circ} \mathrm{C}$ and $120{ }^{\circ} \mathrm{C}$. The overall lubricant flow can be altered from $0.5 \mathrm{l} / \mathrm{min}$ to $20 \mathrm{l} / \mathrm{min}$, and it is controlled by a frequency-converted-driven pump.

The used lubricant was a mineral oil based industrial gear oil equipped with an EP-additive system. The oil is designed for heavy duty gears and the specifications are listed in Table 1.

Table 1. Specification of the lubricant used.

\begin{tabular}{lcc}
\hline & & Value \\
\hline Kin. viscosity $@ \mathbf{4 0} \mathbf{0}^{\circ} \mathrm{C}$ & {$\left[\mathrm{mm}^{2} / \mathrm{s}\right]$} & 150 \\
Kin. viscosity $@ \mathbf{1 0 0}^{\circ} \mathrm{C}$ & {$\left[\mathrm{mm}^{2} / \mathrm{s}\right]$} & 15 \\
Density $@ \mathbf{1 5}^{\circ} \mathrm{C}$ & {$\left[\mathrm{kg} / \mathrm{m}^{3}\right]$} & 897 \\
VG class & {$[-]$} & 150 \\
Flash point (COC) & {$\left[{ }^{\circ} \mathrm{C}\right]$} & 240 \\
Pour point & {$\left[{ }^{\circ} \mathrm{C}\right]$} & -24 \\
\hline
\end{tabular}

\subsection{Discs}

The discs were made of 18CrNiMo7-6 (EN 10084) and case hardened to a surface hardness of 59-61 HRC. In order to minimise any risk of eccentricity error between the bearings and the contact surface, the surfaces were ground as discs assembled on shafts. The outer diameter of the discs is $70 \mathrm{~mm}$ at the contact surface, and the width of the ground area is $10 \mathrm{~mm}$.

The discs on shaft 1 were ground to a radius of $100 \mathrm{~mm}$ 


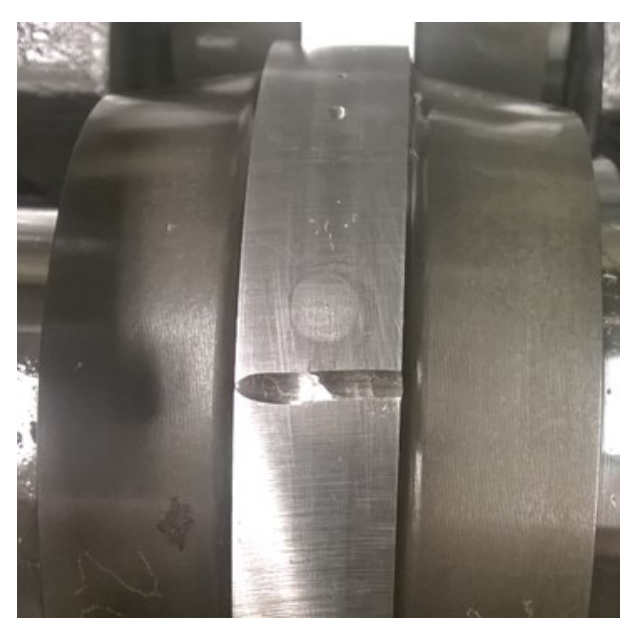

Fig. 2. Disc with grooves. The width of the ground contact area is $10 \mathrm{~mm}$ and the width of the groove in rolling direction is roughly $1.5 \mathrm{~mm}$.

in the axial direction, while the discs on shaft 2 were ground to be flat (illustrated as $r_{1}$ and $r_{2}$ in Fig. 1) resulting in an elliptic pressure distribution ( $p$ in Fig. 1 ) in the contact. The width of the pressure trace is much less than the overall width of the ground surface with the used load allowing grooves that do not cross over the entire ground area (visualized in Fig. 2).

Three grooves were manually ground onto the disc on shaft 2, generating impact-like loading to the bearing when rotating and in contact with the other disc. The grooves were positioned at 90 degrees from each other along the circumference of the disc. In the rolling direction, the width of the groove is roughly $1.5 \mathrm{~mm}$ and the depth about 1 $\mathrm{mm}$.

\subsection{Bearings}

There are four bearings in the test system, as illustrated in Fig. 1. Three of the bearings are two-row spherical roller bearings. They have outer diameter of $62 \mathrm{~mm}$, bore diameter of $30 \mathrm{~mm}$, and width of $20 \mathrm{~mm}$. These bearings contain a total of 30 roller elements divided into two rows and the basic static load rating from them is $60 \mathrm{kN}$, while the basic dynamic load rating is $66.1 \mathrm{kN}$.

A much smaller deep groove ball bearing was installed in the free end of shaft 2 by using suitable adapter parts in order to fit it in the space that was originally designed for the larger bearing. The dynamic and static load ratings for this bearing are $1.53 \mathrm{kN}$ according to the manufacturer [32]. The outer diameter of this bearing is $62 \mathrm{~mm}$, the bore diameter is $50 \mathrm{~mm}$, and the width is $6 \mathrm{~mm}$. There is also a total of 30 rolling elements in this bearing. Both bearings are shown in Fig. 3.

The lubrication condition of the test bearing was closed grease lubrication or splash lubrication with the oil that was lubricating the disc contact inside the device frame. The larger bearings were lubricated with pressured oil flow through them in all the tests.

\subsection{Measurements}

There were three separate data acquisition systems used in the experiments. Firstly, such parameters as lubricant temperature, the normal force and the rotation speeds of the shafts were collected. The second system recorded the acceleration response at the device frame near the observed bearing and the third captured the acoustic emission data close to the observed bearing.

The acceleration response was measured by using a triaxial accelerometer with a measurement range up to $50 \mathrm{~g}$. During data recording, the sampling frequency was set at $20 \mathrm{kHz}$. The sensor was mounted to a threaded pad, which was glued to the frame, as presented in Fig. 4.

The AE sensor was a resonance-type PAC R15D, which resonance frequency is $150 \mathrm{kHz}$. The sensor was placed inside a holder that was mounted to the device frame through a thread connection. A Mistras 2/4/6 preamplifier with $20 \mathrm{~dB}$ amplification was used between the sensor and a Mistras PCI-2 acquisition system for all measurements. The sampling frequency was set at $1 \mathrm{MHz}$.

\section{Experimentation and analysis}

Each test began with a warm-up cycle, while the temperature of the lubricant as well as the bearings were stabilized by circulating the lubrication oil around the

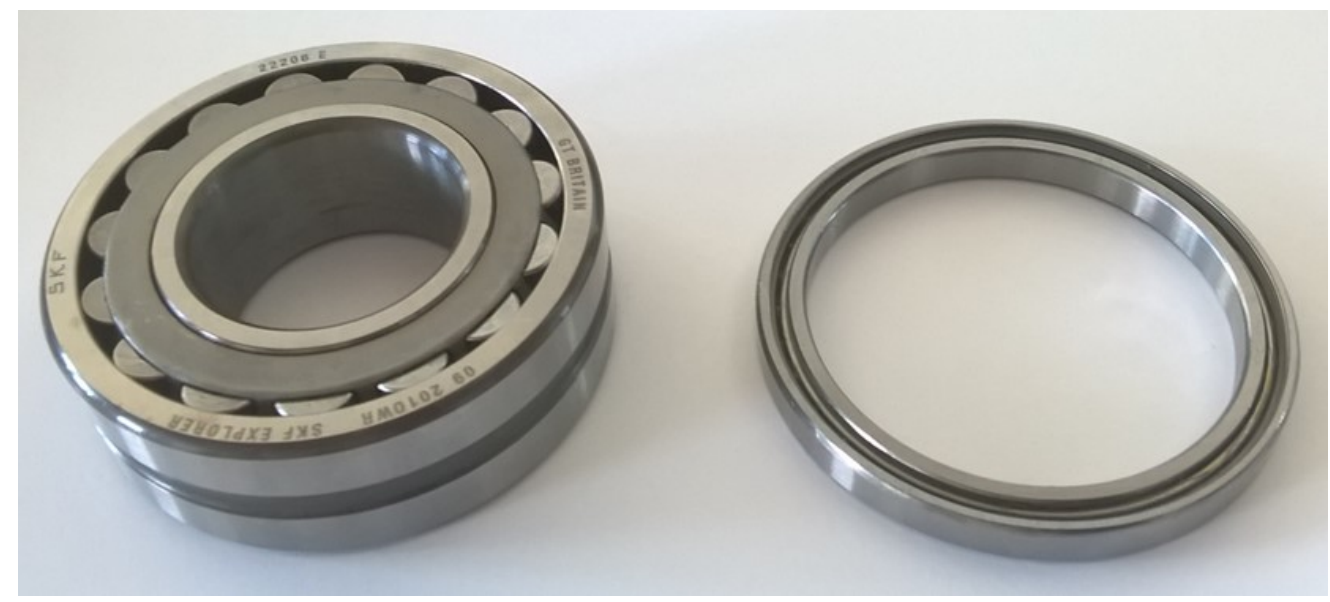

Fig. 3. The spherical roller bearing on the left and the deep groove ball bearing lubricated by grease on the right. The outer diameter of both bearings is $62 \mathrm{~mm}$. 


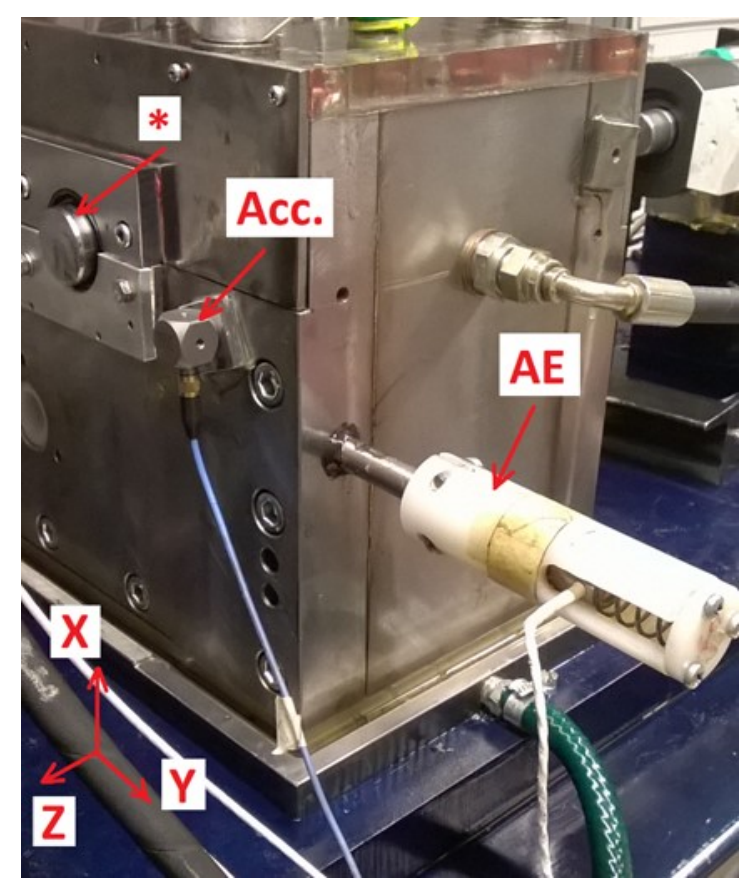

Fig. 4. The used acceleration sensor (Acc.) with measurement directions along with the acoustic emission sensor (AE) inside the holder. The observed bearing was assembled on the shaft marked ${ }^{\star * \prime}$ near the sensor.

bearings and the shafts inside the frame for about one hour. The shafts were not rotated, nor was any radial force applied during this period. The lubricant temperature was set at $60{ }^{\circ} \mathrm{C}$, a typical lubricant temperature in powertrain transmissions [33, 34]. During all the tests the rotation speed of the shafts was 1200 RPM. The load was set at 4.5 $\mathrm{kN}$, yielding a radial load of $2.25 \mathrm{kN}$ on the observed bearing, which is roughly 1.5 times higher than the load rating of the bearing. Since the aim of the study was to observe the behaviour of the parameter values indicating about damage over the bearing lifespan, this high load was used to shorten the period needed for the tests. The following test cases were conducted:

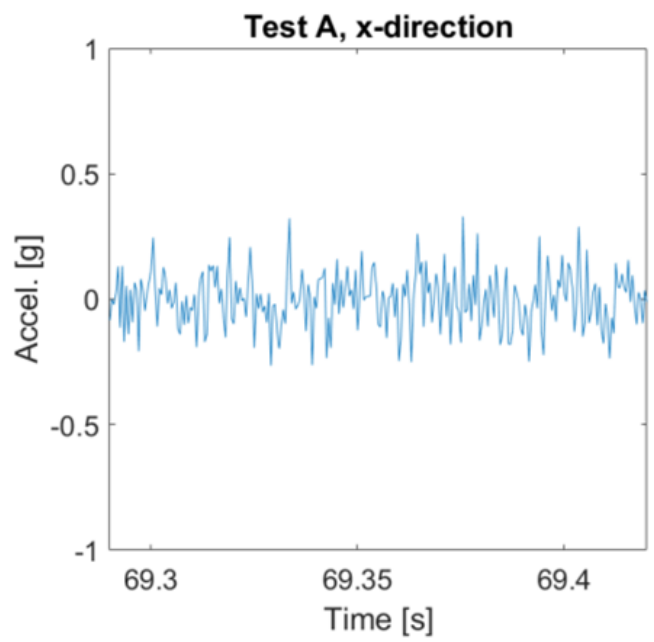

A. Constant load and grease lubrication

B. Constant load and splash lubrication inside the device frame

C. Constant load with non-load periods and grease lubrication

D. Constant load combined with impact loads and nonload periods with grease lubrication

The tests were stopped when a significant increase in the acceleration level was reached or an unnecessary loud noise was recognized during operation, indicating significant damage in the bearing.

\subsection{Analysis of acceleration signals}

Firstly, band pass filtering from $2 \mathrm{~Hz}$ to $10 \mathrm{kHz}$ was applied to the measured signal. The subsequent examination included calculation of the kurtosis, the crest factor and the RMS values over the test period.

\subsubsection{Basic parameters}

Root mean square can be used to compare two dynamic signals. The RMS value indicates the energy of the vibration oscillation. The RMS $x_{R M S}$ of a signal $x(t)$ is defined [35]:

$$
x_{R M S}=\sqrt{\frac{1}{\tau} \int_{0}^{t} x^{2}(t) d t}
$$

Where $\tau$ is the averaging time of the observation period. An increasing value along with time can be considered as an indication of change in the structure's stiffness or the progression of a failure.

Crest factor $c_{\mathrm{x}}$ is a parameter of a waveform of signal $x$ (n) showing the ratio of the peak value in the signal to the effective value $x_{r m s}$ [36]:

$$
c_{x}=\frac{\max ([x(n)])}{x_{r m s}}
$$

It indicates the extreme of the peaks within the signal. During failure progression, the magnitude of the peaks tends to grow, leading to an increase in the crest factor value. However, after further progression, also the

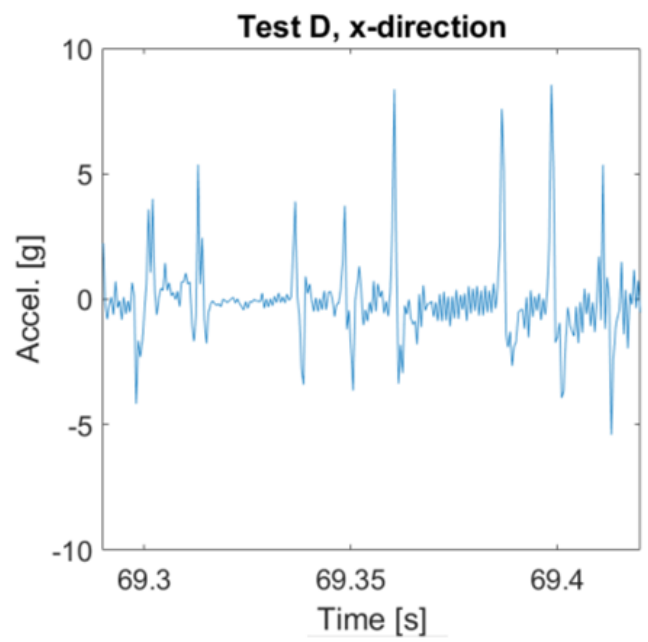

Fig. 5. Typical acceleration signals without (test A) and with (test D) impact loading in the time domain. 

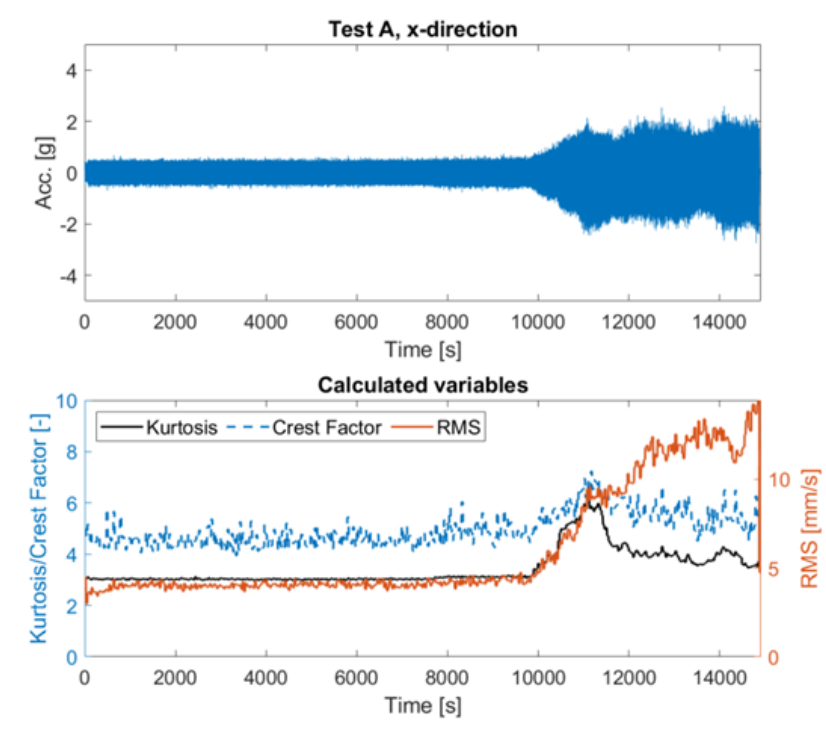
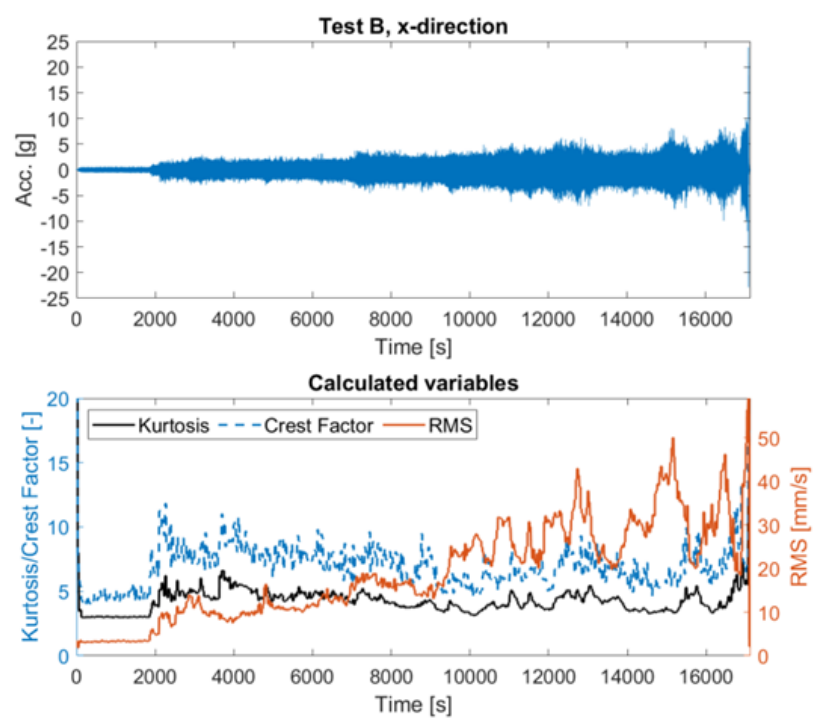

Fig. 6. The acceleration signals and kurtosis, crest factor, and RMS values during tests A and B.

effective value increases and consequently the influence of the peaks decreases, reducing the crest factor value.

Kurtosis is a statistical parameter searching for possible deviations in the analysed data. Kurtosis $K_{t}$ can be regarded as comparing the tails of the probability density function with that of the normal distribution [35]:

$$
K_{t}=\frac{M_{4}}{\sigma^{4}}
$$

where $\sigma^{2}$ is variance and $M_{4}$ is the fourth central moment, which can be written as expectation $E(1)$ with the time varying signal $x(\mathrm{t})$ and estimator of the mean $\bar{x}$ [35]:

$$
M_{4}=E(l)=E\left[(x-\bar{x})^{4}\right]
$$

The vibration content of an undamaged bearing is assumed to be normally distributed and yielding a kurtosis value of 3 . When the kurtosis value is higher, the distribution has "larger tails" and vice versa when the kurtosis is below 3. Larger tails are considered as an indication of high peaks in the observed signal, which may have originated from damage in the bearing parts.

\subsection{Analysis of acoustic emission data}

AE signals can be divided into two categories: burst (transient) signals and continuous signals. A continuous AE signal may be used to observe for example the result of friction in a sliding contact, such as in bearings, while burst signals result from short duration releases of energy, for instance, as in fatigue crack growth.

Parameters defining characteristics of AE activity are often calculated over "AE hits". An AE hit begins when the $\mathrm{AE}$ signal crosses an evaluation threshold voltage and is considered to end after the signal has remained below the threshold value for a certain period (hit definition time, HDT) [8]. In this paper, two of the available parameters calculated by the software of the equipment provider from a continuous signal are monitored [36]:
- $\mathrm{AE}$ energy as the time integral of the absolute signal voltage

- AE RMS as the root mean square voltage

The peak definition time was set at $200 \mu$ s and the hit definition time at $800 \mu \mathrm{s}$. The hit lockout time to inhibit the measurement reflections and late-arriving parts was set at $1000 \mu \mathrm{s}$ and the maximum duration at $100 \mathrm{~ms}$.

\section{Results and discussion}

The lubricant temperature and the radial load varied slightly during the tests. Typically, the lubricant temperature oscillated between $58.5^{\circ} \mathrm{C}$ and $61.5^{\circ} \mathrm{C}$ and the radial force deviated roughly by a maximum of $\pm 10 \%$ from the setting value. It was assumed that the spread in these parameters had only a diminishing effect on the analysis results.

The x-direction of the recorded acceleration data was used in the detailed analysis, since the largest changes in the signals were found to occur in this direction. The kurtosis, crest factor and RMS values were calculated in sections of $30 \mathrm{~s}$ over the entire test period in order to observe how these values change as damage progresses.

The graphs in Fig. 5 show the typical shapes of the measured acceleration signals during the device operation with and without the impact loading. The three consecutive response impulses originating from the grooves on the disc are clearly visible in the right graph, reaching much higher amplitudes in comparison to the condition in the left graph without the influence of the impact load.

\subsection{Damage indicators}

Fig. 6 presents the recorded acceleration signal and the variation of the calculated parameters over tests A and B. A constant amplitude oscillation phase can be seen at the beginning of the tests until about $10000 \mathrm{~s}$ in test $\mathrm{A}$ and until about $2000 \mathrm{~s}$ in test B. During this period, the kurtosis values in both tests are roughly 3 , indicating damage-free 

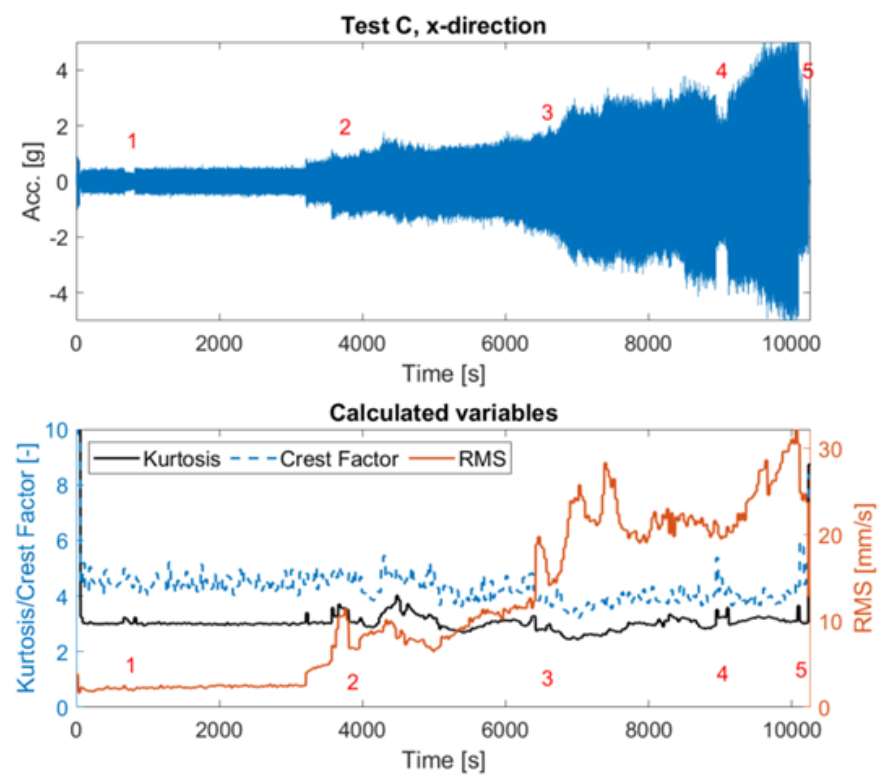

Fig. 7. The acceleration signal and kurtosis, crest factor and RMS values during test $C$. The periods without loading are illustrated with numbers 1 to 5 in the graphs.

bearings. The RMS values also remain relatively unchanged, but some deviation can be seen in the crest factor curve.

After a change point (test A at $10000 \mathrm{~s}$, test B at $2000 \mathrm{~s}$ ), a significant increase in the acceleration signals can be noted, which is also visible in the calculated curves. This is probably the moment of damage initiation or the moment when the progression of damage in the bearings starts to be so substantial that it is noticed with the measurement equipment. This can be clearly seen in all the curves except the crest factor -curve in test $\mathrm{A}$, where the increase is somewhat uncertain.

After the change-point, an increasing trend can be noted in the RMS curve for both tests A and B. However, in the kurtosis and the crest factor curves, this behaviour seems to be much less, and the curves just remain on a slightly elevated level (with variation) in comparison to the first, stable part of the test. This result suggests that the kurtosis, RMS, and partly also the crest factor values can be used to track initiation of the bearing damage, but only RMS may show a reliable result in monitoring the progression.

It can be seen in Fig. 6 that at the end of test B, the acceleration values increase significantly. This is also visible in the RMS curve as well as mildly in crest factor and kurtosis curves. The reason for this sudden step-up is that at the end of the test the rolling elements broke into pieces.

\subsubsection{Effect of load}

In Fig. 7 are illustrated the acceleration signal and the calculated variables during test $C$ as well as five approximately $3 \mathrm{~min}$ long non-load periods, where the radial load was roughly $100 \mathrm{~N}$.

The stable (damage-free) period at the beginning of test
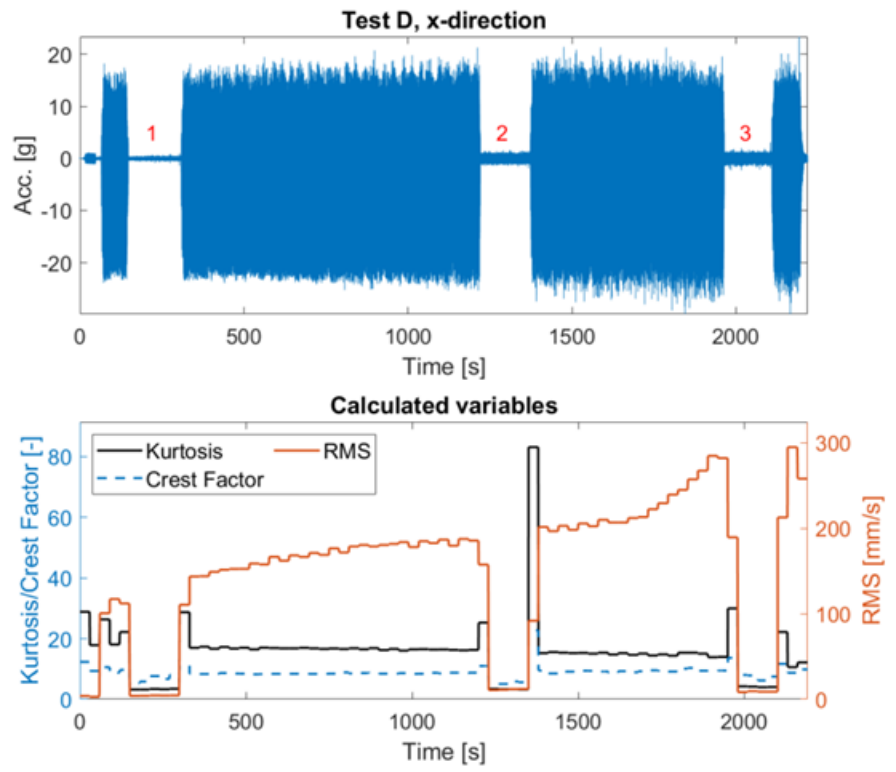

Fig. 8. The measured acceleration signal in the upper graph and the kurtosis, crest factor and RMS values during test D in the lower graph. The periods without loading are illustrated with the numbers 1 to 3 in the middle of the upper graph.

C is clearly visible in the similar way as in tests A and B, although a large increase especially in the kurtosis curve can be noted at the start. This step-up originates from the rough start-up of the system, while the measured acceleration signal values are slightly higher than in the stabilized stage.

After initiation of damage (at roughly $3600 \mathrm{~s}$ in Fig. 7) the acceleration and consequently the RMS curves start to climb. Also, the kurtosis and the crest factor values elevate and vary more than in the previous part of the test. However, during load-free periods, minor increases can be seen in the kurtosis and the crest factor curves probably most clearly illustrated in locations 1 and 4 . When returning to the loaded stage of testing, the curves seem to come back to the same level as before the non-load period. In the RMS curve this phenomenon is the opposite, as the value decreases during the non-loaded period in a similar way as the acceleration amplitude.

Fig. 8 illustrates results from test D. The amplitude of the acceleration curve is much higher in comparison to the other tests because of the impact loading and it also

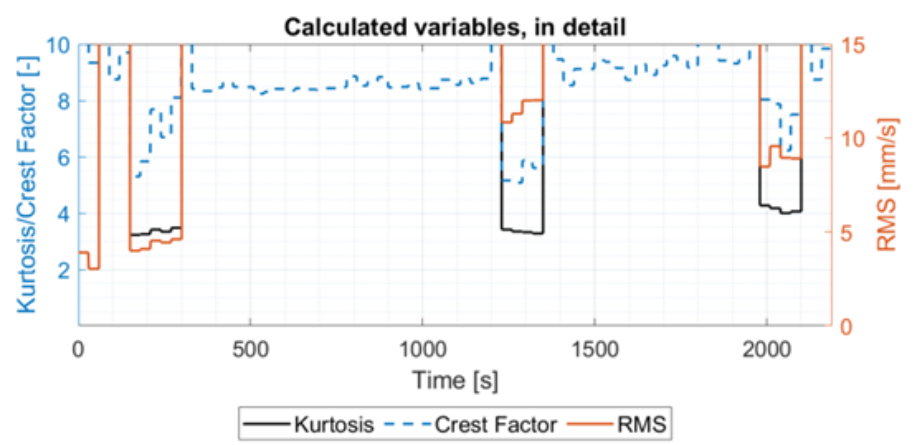

Fig. 9. The kurtosis, crest factor and RMS values during test $\mathrm{D}$ in detail. 

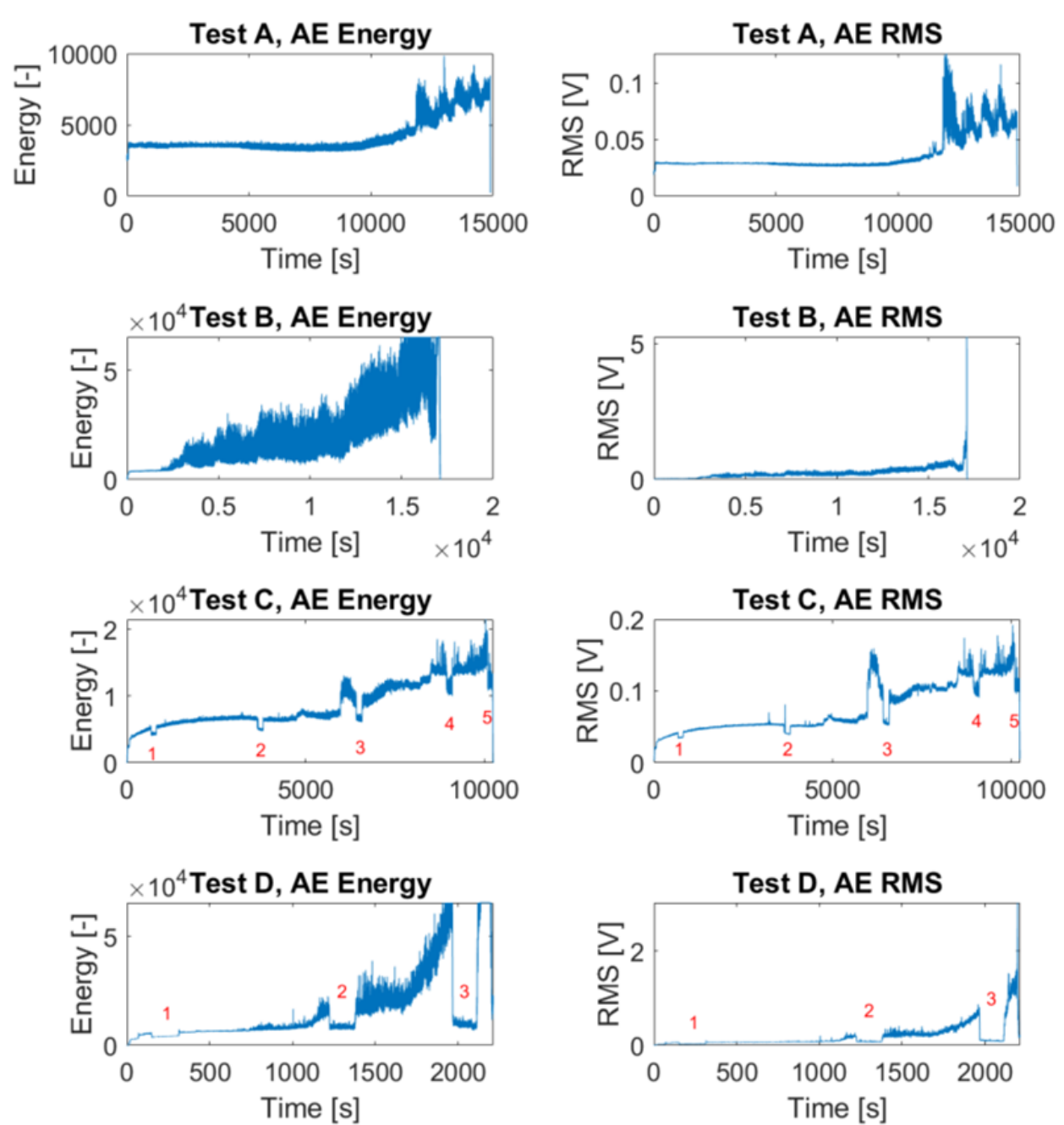

Fig. 10. Development of AE energy and AE RMS values during tests A to D. The periods without loading are illustrated with numbers 1 to 5 and 1 to 3 in the graphs.

remains rather constant until the end of the test, which is quite the opposite when compared to the results of tests A, $\mathrm{B}$ and $\mathrm{C}$. This means that the impact loading is dominating the measured signal content and detection of weaker signals originating possibly from damage in the bearing becomes challenging. Furthermore, although a slight increasing trend can be seen in the RMS curve over the test period indicating progression of damage, the destruction of the rolling elements, taking place at the end of the test, is suppressed by the impact loading and it is not visible in the curves.

The relatively high values of the kurtosis $(>3)$ and crest factor $(>8)$ can be seen throughout the test, while the impact loading is applied to the system. Basically, this falsely indicates bearing damage. Elevated values of kurtosis can be noted also on both sides of the non-loaded periods, caused by the evaluation procedure, where the analysed period of the signal includes both load conditions at these locations.

Fig. 9 shows the calculated curves in detail to visualize the values during non-loaded periods. A slightly rising trend of the kurtosis values can be noted from roughly 3.4 at $220 \mathrm{~s}$ and 3.3 at $1300 \mathrm{~s}$ to 4.2 at $2000 \mathrm{~s}$, indicating damage progression. When observing the crest factor curve, this trend is not as clearly visible and the RMS value at the third non-load period at approximately $2000 \mathrm{~s}(8.9)$ is lower than at $1300 \mathrm{~s}(12)$, leading to an unreliable conclusion about the bearing condition.

The above results suggest that the conclusion as to whether the bearing is damaged or not is clearer if done during non-loaded periods when observing kurtosis values. On the other hand, if the trend of the RMS value is monitored, results from periods when loading is applied to the system may lead to higher reliability, at least in situations when working in stable load regime.

\subsection{Acoustic emission data}

The development of the acoustic emission energy and the AE RMS values during all the tests are presented in Fig. 10. In general, a relatively stable period is visible in all the curves at the beginning of each test. However, after a certain point, the level and the variation of the curve values start to increase indicating initiation and progression of damage in the monitored bearing, as seen clearly, for instance, in the AE energy curve in test B after approximately 2000 s. This was similarly notable in the 
Outer race

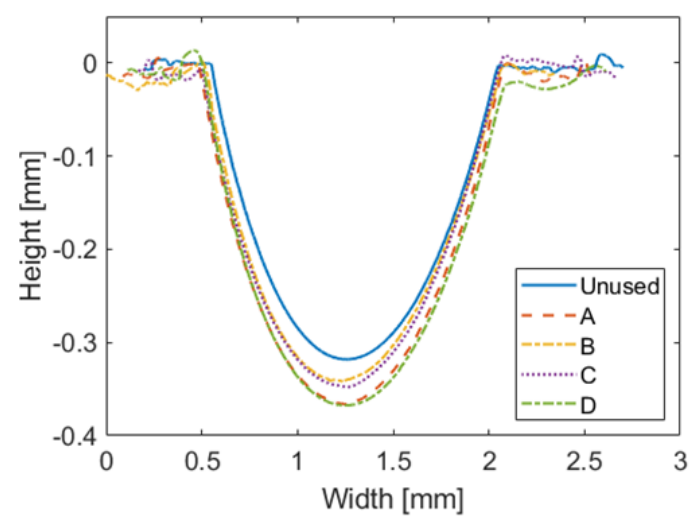

Inner race

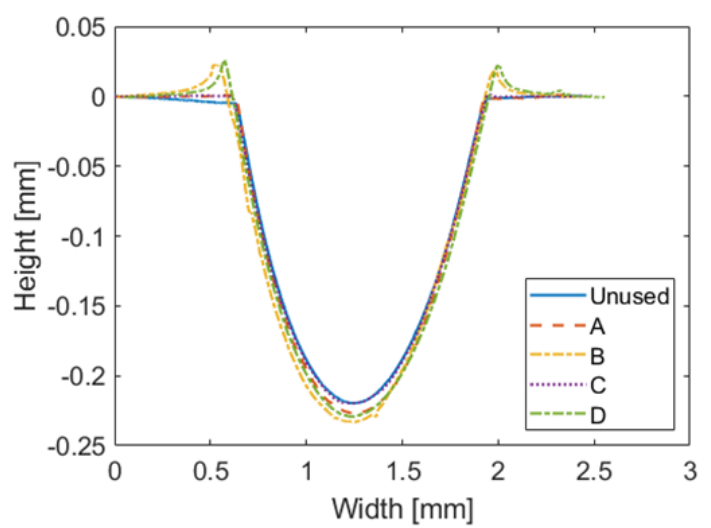

Fig. 11. Comparison of the profile curves between unused and tested bearings. The curves for the outer race are on the left and for the inner race on the right.

curves calculated from the acceleration data as well. Furthermore, a very high peak can be seen in test $\mathrm{B}$ at the end of the AE RMS curve, which is caused by the destruction of the rolling elements inside the bearing. In the AE energy curve of test $\mathrm{B}$, this peak was cut-off because of the settings of the measurement equipment. This behaviour can be seen also in the curve for test $\mathrm{D}$.

The AE curves in test $\mathrm{D}$ seem not to be much disturbed by the impact loading since high levels or variation cannot be seen in the first part of the curves at the stage when the bearing was still practically undamaged. Furthermore, the initiation of bearing damage seems to be visible at about $650 \mathrm{~s}$, when especially the AE energy values start to vary substantially. As the damage progresses, a clear increasing trend can be noted in both AE curves towards the end of the test. This phenomenon is mostly lacking from the curves based on the measured acceleration data in Fig. 8, except the slight rise of the RMS values at the end of the test.

Furthermore, periods without load can be seen in the AE based curves as significant decrease in the curve level. This is clearly visible especially in test D where the impact loading was applied to the system. Since this change is relatively substantial in the latter part of the test, when the damage has progressed significantly, the reason for it is probably not the lack of impact loading interfering with the measured signal, but the absence of damaging events in the bearing because of much lower load.

The above suggests that the $\mathrm{AE}$ measurement is probably quite effectively capturing only the crack propagation events in the bearing parts and neglecting the external impact loading, which is obviously acting on a much lower frequency range than the resonance frequency of the AE sensor.

\subsection{Profile measurement and raceways}

Profiles curves over the bearing races were recorded by using a profilometer, which is primarily designed to evaluate surface roughness through mechanical measurement. Typical profile curves measured across the outer and inner races of the test bearings are presented in
Fig. 11. The raceway for the rolling elements is clearly visible in both graphs. The comparison of the profile curves shows significant difference between an unused bearing and the tested bearings except for the inner race of test $C$, although its outer race profile differed substantially from the unused.

The main conclusion from the comparison of the graphs in Fig. 11 is that the wear/deformation was relatively larger in the outer race than in the inner race. In addition to changes in the bottom of the rolling path, significant increases can be noted in the inner race curves of tests $B$ and $\mathrm{D}$ on both sides of the actual raceway. Since these deformations are missing from the curves of tests A and C, they may have resulted because of the breakdown of the rolling elements at the end of the tests.

The surface bottom areas of the outer and the inner raceways of an unused bearing as well as of the bearings from tests $\mathrm{A}$ and $\mathrm{C}$ were inspected by using an optical microscope. The raceways of tests $B$ and D were left out from the examination because the surfaces in these tests were not representing the actual wear surface due to loading, since they were significantly worked in the end of the tests during the breakdown of the rolling elements. Typical outcome of the inspections is shown in Fig. 12. In all the pictures the machining grooves in the rolling (vertical) direction are visible, which indicates that the found difference between the unused and tested profile curves presented in Fig. 11, is probably mainly caused by plastic deformation under high loading than wear.

In addition, the overloading of the bearings during the tests lead to cracking on the outer raceways as seen in Fig. 12. Since the number of load cycles in tests $A$ and $C$ were relatively low (test A: $\sim 298000$ cycles, test C: $\sim 206000$ cycles), the cracks are still probably at the beginning stage of developing into pits. According to the results of the tests $\mathrm{B}$ and $\mathrm{D}$, it can be assumed that if the testing periods would have been continued, the rolling elements would have broken into pieces most probably before the cracks would have propagated through the outer race.

The raceway surfaces for the inner parts of the bearing from tests $\mathrm{A}$ and $\mathrm{C}$ resemble more the unused raceway 

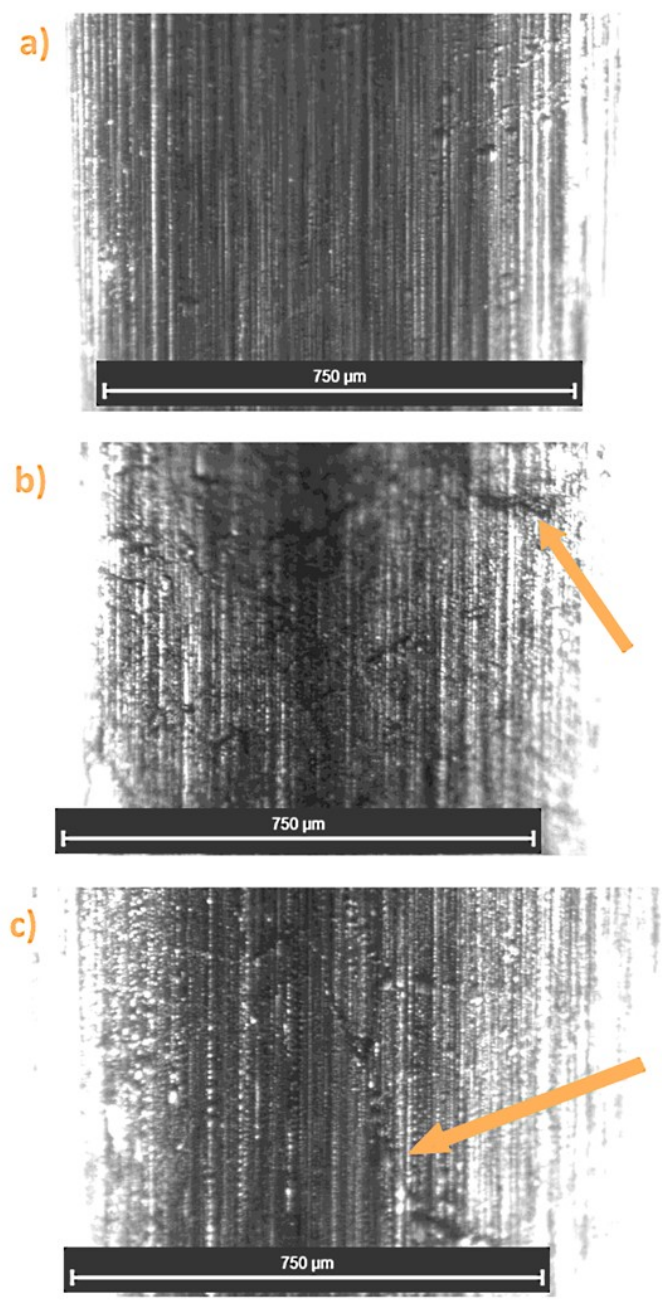
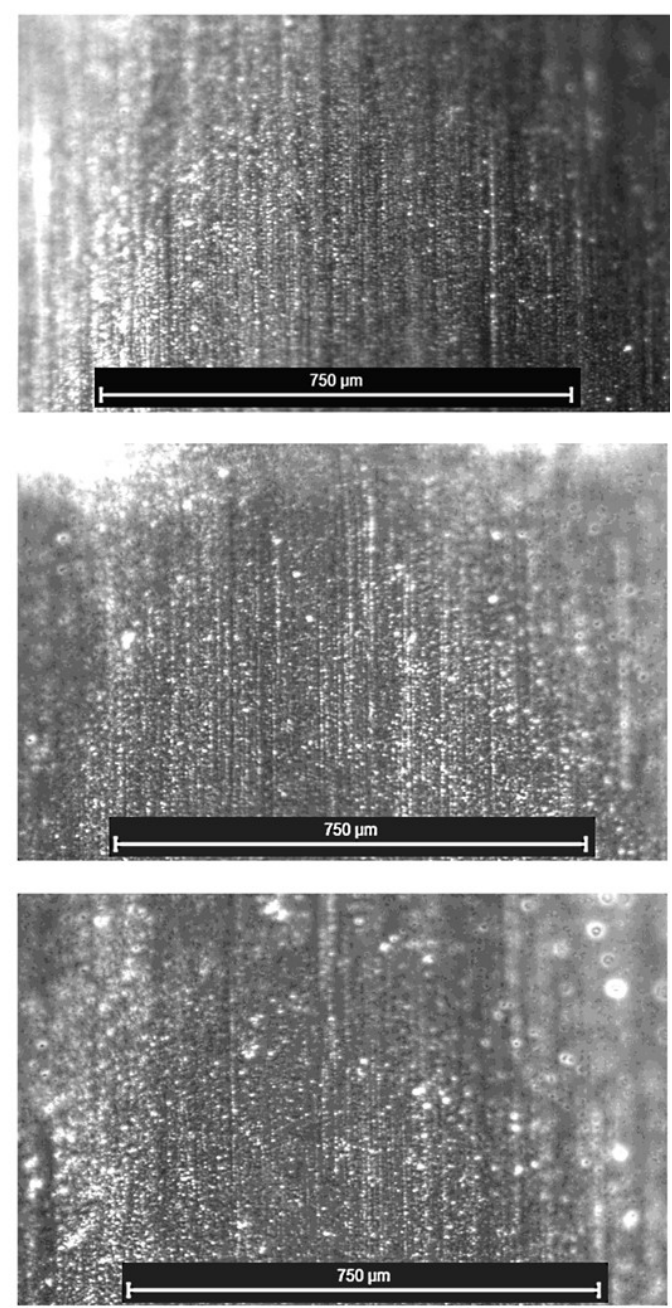

Fig. 12. Magnification of the bottom areas in the middle of the outer raceways on the left and inner raceways on the right. The pictures from top to bottom represent the unused bearing (a), the bearing from test $A(b)$ and the bearing from test $C(c)$. The arrows point out cracks on the surfaces.

than the surfaces of the outer raceways. This suggests that the outer races have been more stressed during these accelerated tests in comparison to the inner races, which was also the conclusion drawn from the results of the profile measurements.

\section{Conclusions}

In this paper, the behaviour of parameters used to detect rolling element bearing damage were studied over the lifespan of a bearing in accelerated (high load level) bearing tests. The explored deep groove ball bearings were loaded with a constant radial force or combined constant and impact loading. The main conclusions are as follows:

- During the conducted tests the rolling elements seemed to be the most stressed part in the bearings and the outer races suffered more plastic deformation than the inner races.

- The results suggest that in an impact-free load situation the trends of the kurtosis, RMS and partly also crest factor values calculated from the acceleration data can be used to track whether the bearing is damaged or not, but only the RMS may show indication about progression of the damage.

- The kurtosis and the crest factor values do not show reliably the bearing condition when impact loading is interfering with the monitored system. However, the RMS trend may slightly indicate damage progression in such situation.

- AE energy and AE RMS trends can indicate bearing damage and show progression of the damage whether the bearing is operating under impact loading or not.

In many real-world constructions the load condition is demanding, decreasing the reliability of conclusions about bearing condition based on measured acceleration response. This challenge can be overcome by utilizing $\mathrm{AE}$ measurements, which also opens possibilities for detailed monitoring and research of bearing damage progression.

\section{Acknowledgements}

The research work has been carried out under the auspices of the project OPMO - Operation monitoring of mineral crushing machinery. This activity has received funding from the European Institute of Innovation and 
Technology (EIT RawMaterials project number 18253). This body of the European Union receives support from the European Union's Horizon 2020 research and innovation programme. The funder has had no influence on the content of this paper.

\section{References}

[1] ISO 20816-1:2016: Mechanical vibration - Measurement and evaluation of machine vibration. Part 1: General guidelines.

[2] ISO 13373-3:2015: Condition monitoring and diagnostics of machines. Vibration condition monitoring. Part 3: Guidelines for vibration diagnosis.

[3] Randall RB. Vibration-based condition monitoring: Industrial, Aerospace and Automotive Applications. John Wiley \& Sons Ltd 2011. 289 p. https:// doi.org/10.1002/9780470977668

[4] Borghesani P, Ricci R, Chatterton S, Pennacchi P. A new procedure for using envelope analysis for rolling element bearing diagnostics in variable operating conditions. Mech. Systems and Signal Processing 2013;38(1);23-35. https://doi.org/10.1016/j.ymssp.2012.09.014.

[5] Randall RB, Antoni J. Review. Rolling element bearing diagnostics-A tutorial. Mechanical Systems and Signal Processing, 2011;25;485-520. https://doi.org/10.1016/ j.ymssp.2010.07.017

[6] Smith WA, Borghesani P, Ni Q, Wang K, Peng Z. Optimal demodulation-band selection for envelope-based diagnostics: A comparative study of traditional and novel tools. Mech Syst Sig Process, 2019;134;1-24. https:// doi.org/10.1016/j.ymssp.2019.106303

[7] Sawalhi N, Randall RB, Endo H. The enhancement of fault detection and diagnosis in rolling element bearings using minimum entropy deconvolution combined with spectral kurtosis. Mech. Systems and Signal Processing 2007;21;2616-2633. https:// doi.org/10.1016/ j.ymssp.2006.12.002

[8] Ohtsu M, Enoki M, Mizutani Y, Shigeishi M. Principles of the acoustic emission (AE) method and signal processing, in: Practical acoustic emission testing. The Japanese society for non-destructive inspection. Springer 2016. pp. 5-35. https://doi.org/10.1007/978-4-431-55072-3_2

[9] Van Hecke B, Yoon J, He D. Low speed bearing fault diagnosis using acoustic emission sensors. Applied Acoustics, 2016;105;35-44. https:// doi.org/10.1016/ j.apacoust.2015.10.028

[10] Mba D. Acoustic Emissions and Monitoring Bearing Health. Trib. Transactions, 2003;3;447-51. https:// doi.org/10.1080/10402000308982649

[11] Chacon JLF, Kappatos V, Balachandran W, Gan TH. A novel approach for incipient defect detection in rolling bearings using acoustic emission technique. Applied Acoustics, 2015;89;88-100. https://doi.org/10.1016/ j.apacoust.2014.09.002

[12] Elasha F, Greaves M, Mba D, Fang D. A comparative study of the effectiveness of vibration and acoustic emission in diagnosing a defective bearing in a planetry gearbox. Applied Acoustics, 2017;115;181-195. https:// doi.org/10.1016/j.apacoust.2016.07.026

[13] Cornel D, Gutiérrez Guzmán F, Jacobs G, Neumann S. Condition monitoring of roller bearings using acoustic emission. Wind Energ. Sci. 2021;6;367-76. https:// doi.org/10.5194/wes-6-367-2021

[14] Vlcek BL, Zaretsky EV. Rolling-element fatigue testing and data analysis - A tutorial. Trib. Transactions, 2011;54;523-41. https:// doi.org/10.1080/10402004.2011.568673

[15] Brizmer, V, Gabelli A, Vieillard C, Morales-espejel GE. An experimental and theoretical study of hybrid bearing micropitting performance under reduced lubrication. Trib. Transactions 2015;58;829-35. https:// doi.org/10.1080/10402004.2015.1021944

[16] Fowell M, Ioannides S, Kadiric A. An Experimental Investigation into the Onset of Smearing Damage in Nonconformal Contacts with Application to Roller Bearings. Trib. Transactions 2014;57;472-88. https:// doi.org/10.1080/10402004.2013.875607

[17] Pape F, Terwey JT, Wiesker S, Averbeck S, Muhmann C, Lipinsky D. Tribological research on the development of white etching cracks (WECs). Forsch Ingenieurwes 2018;82;341-352. https:// doi.org/10.1007/s10010-018$\underline{0289-6}$

[18] Harris TA., Kotzalas MN. Advanced Concepts of Bearing Technology: Rolling Bearing Analysis, Fifth Edition, CRC Press LLC, Taylor \& Francis Group, 2007. https://doi.org/10.1201/9781420006582

[19] Galbato, AT. Methods of Testing for Rolling Contact Fatigue of Bearing Steels. Rolling Contact Fatigue Testing of Bearing Steels, Hoo, J. J. C. (Ed.), American Society of Testing Materials: Philadelphia, 1982, pp 169189. https:// doi.org/10.1520/STP36139S

[20] Barszcz T, Sawalhi N. Fault detection enhancement in rolling element bearings using the minimum entropy deconvolution. Arch Acoust 2012;37(2):131-141. https://doi.org/10.2478/v10168-012-0019-2

[21] Al-Bugharbee H, Trendafilova I. A fault diagnosis methodology for rolling element bearings based on advanced signal pretreatment and autoregressive modelling. Journal of Sound and Vibration, 2016;369;246-265. https:// doi.org/10.1016/ j.jsv.2015.12.052

[22] Junchao Guo a, Hao Zhang a, Dong Zhen a, $\Uparrow$, Zhanqun Shi a, Fengshou Gu b, Andrew. D. Ball. An enhanced modulation signal bispectrum analysis for bearing fault detection based on non-Gaussian noise suppression. Measurement, 2020;151(107240); https:// doi.org/10.1016/j.measurement.2019.107240

[23] Ahlroos T, Ronkainen H, Helle A, Parikka R, Virta J, Varjus S. Twin disc micropitting tests. Tribol Int 2009;42;1460-6. https://doi.org/10.1016/ j.triboint.2009.05.023 
[24] Oila A, Bull SJ. Assessment of the factors influencing micropitting in rolling/sliding contacts. Wear 2005;258;1510-24. https://doi.org/10.1016/ j.wear.2004.10.012

[25] Kleemola J, Lehtovaara A. Experimental evaluation of friction between contacting discs for the simulation of gear contact. TriboTest 2007;13(1):13-20. https:// doi.org/10.1002/tt.29

[26] Johansson J. On the influence of gear oil properties on pitting life. Luleå Sweden: Dissertation, Luleå University of Technology; 2015.

[27] Tassini N, Quost X, Lewis R, Dwyer-Joyce R, Ariaudo C, Kuka N. A numerical model of twin disc test arrangement for the evaluation of railway wheel wear prediction methods. Wear 2010;268:660-7. https:// doi.org/10.1016/j.wear.2009.11.003

[28] Höhn B-R, Michaelis K, Kreil O. Influence of surface roughness on pressure distribution and film thickness in EHL-contacts. Tribol Int 2006;39:1719-25. https:// doi.org/10.1016/j.triboint.2006.01.008

[29] Savolainen M, Lehtovaara A. An experimental approach for investigating scuffing initiation due to overload cycles with a twin-disc test device. Tribol Int 2017;109:311-8. https:// doi.org/10.1016/ j.triboint.2017.01.005

[30] Savolainen M, Lehtovaara A. An experimental investigation of scuffing initiation due to axial displacement in a rolling/sliding contact. Tribol Int 2018;119:688-97. https://doi.org/10.1016/ j.triboint.2017.12.007

[31] Savolainen M, Lehtovaara A. An approach to investigating subsurface fatigue in a rolling/sliding contact. Int J Fatigue 2018; 117: 180-188. https:// doi.org/10.1016/j.ijfatigue.2018.08.014

[32] https:/ / www.skfbearingselect.com/\#/size-lubrication/ single-bearing [Accessed 21.6.21]

[33] AGMA 925-A03. Effect of lubrication on gear surface distress 2003.

[34] Hammami M, Martins R, Abbesb MS, Haddarb M, Seabra J. Axle gear oils: Tribological characterization under full film lubrication. Tribol Int 2017;106;109-22. https://doi.org/10.1016/j.triboint.2016.05.051

[35] Brandt A. Noise and Vibration Analysis: Signal Analysis and Experimental Procedures. Wiley, 2010. 438 p. https://doi.org/10.1002/9780470978160

[36] Mistras Group Inc. AEwin ${ }^{\mathrm{TM}}$ Software Users's manual, rev 4, October, 2014. 